\title{
New species of Acoela (Acoelomorpha) from the Gulf of California
}

\author{
MATTHEW D. HOOGE \& NEIL EPPINGER \\ Department of Biological Sciences, The University of Maine, 5751 Murray Hall, \\ Orono, ME, 04469-5751,USA. E-Mail: hooge@umit.maine.edu
}

\begin{abstract}
From a survey of interstitial acoel flatworms at San Felipe Bay, Baja California, Mexico, the new species Haplogonaria amarilla sp. nov. (Haploposthiidae), Isodiametra bajaensis sp. nov. (Isodiametridae), Praeaphanostoma gusana sp. nov. (Isodiametridae) are described.
\end{abstract}

Key words: Meiofauna, turbellarians, Platyhelminthes, interstitial, Haplogonaria, Isodiametra, Praeaphanostoma

\section{Introduction}

To date, there is only one species of acoel known from Baja California, Mexico, Solenofilomorpha guaymensis Crezée, 1975, an interstitial species collected subtidally from Guaymas, Sonora (Crezée 1975, see also Tyler et al. 2005). As part of an ongoing investigation of the taxonomy and biogeography of the Acoela (Hooge 2003, Hooge \& Smith 2004, Hooge \& Tyler 2001, 2003a,b, 2005), we collected acoels from San Felipe Bay, Baja, Mexico in February 2004. We report here our finding of three previously unknown species.

\section{Materials and Methods}

Sediment samples were collected on February 1, 2004 in Baja California, Mexico, and transported to Scripps Institution of Oceanography for extraction and observation of the animals. Specimens were extracted from sediment using magnesium-sulfate anesthetization (Sterrer 1971). Live animals were viewed by light microscopy in squeeze preparations and photographed.

For histological study, specimens were relaxed in isotonic magnesium sulfate, fixed in 
warm Stefanini's fixative (Stefanini et al. 1967), washed in phosphate buffer (Millonig's, $0.1 \mathrm{M})$, fixed in phosphate-buffered $1 \%(\mathrm{v} / \mathrm{v})$ osmium tetroxide, dehydrated in acetone, and embedded in EMBed/Araldite epoxy resin. Dehydration was quickened by microwave radiation (Samsung oven, two 7 -sec irradiations at $650 \mathrm{~W}$ separated by 20 -sec interim, with specimen-vial on ice and with water ballast of two filled 300-ml beakers (Giberson \& Demaree, 1995). Serial thick sections of $1.5 \mu \mathrm{m}$ were made according to Smith and Tyler (1984) and stained with toluidine blue.

Body wall musculature was revealed through F-actin staining of whole mounts with fluorescently labeled phalloidin (Alexa 488; Molecular probes, Eugene, OR) according to Hooge (2001).

Type material has been deposited in the American Museum of Natural History (AMNH), New York, New York, USA.

\section{Results}

Family Haploposthiidae Westblad, 1948

Genus Haplogonaria Dörjes, 1968

Haplogonaria amarilla sp. nov. (Figs. 1-3)

Type Material: Holotype. AMNH PLATY 1658, one set of $1.5-\mu \mathrm{m}$-thick serial sagittal sections of epoxy-embedded specimens stained with toluidine blue. Paratypes. AMNH PLATY 1659, one set of 1.5- $\mu$ m-thick serial sagittal sections of epoxy-embedded specimens stained with toluidine blue, and AMNH PLATY 1660, epoxy-embedded whole mount.

Type Locality. San Felipe, Baja California, medium grained sand from a small pool of standing sea water at the high intertidal from the south side of San Felipe Bay (30॰58'35.1”N, 11448’22.6”'W).

Other Material Examined. Living specimens in squeeze preparations; three sets of $1.5-\mu \mathrm{m}$-thick serial sections of epoxy-embedded specimens; several whole mounts for fluorescence imaging of musculature.

Etymology. Species name is a derivation of the Spanish amarillo, yellow, referring to the species body color.

Description. Mature, living specimens up to $650 \mu \mathrm{m}$ long and $150 \mu \mathrm{m}$ wide (Figs. 1A, 2). Preserved specimens contracted to approximately $360 \mu \mathrm{m}$ long and $140 \mu \mathrm{m}$ wide (Figs. 1B, 3). Body cylindrical. Anterior and posterior ends rounded. Body color yellow by transmitted light.

Epidermis completely ciliated. Many large rhabdoid glands present; mostly concentrated at anterior end (Figs. 1, 2).

Musculature with circular muscles that encircle the body along entire length of animal; straight longitudinal muscles present between frontal organ and anterior edge of mouth; 
longitudinal-cross-over muscles (fibers with a longitudinal orientation anteriorly, but bend medially to cross diagonally) present in both dorsal and ventral body wall; anterior end with ventral diagonal muscles positioned between outer circular and inner longitudinal muscles (Fig. 3A).

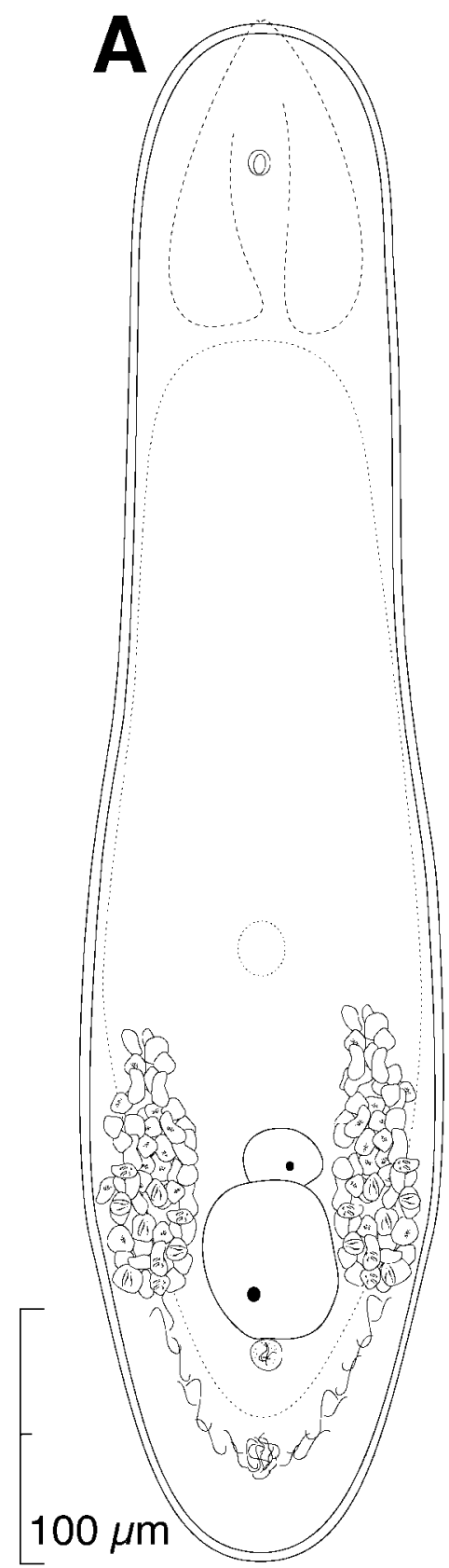

st

fg
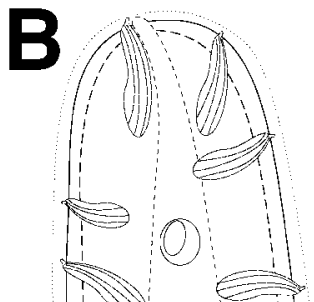

$\lg$

CS

cs

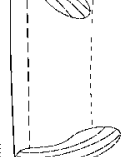

m

$\mathrm{m}$

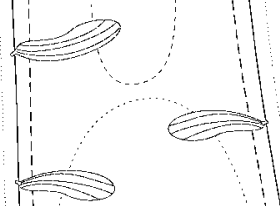

$\mathrm{t}$

e

e

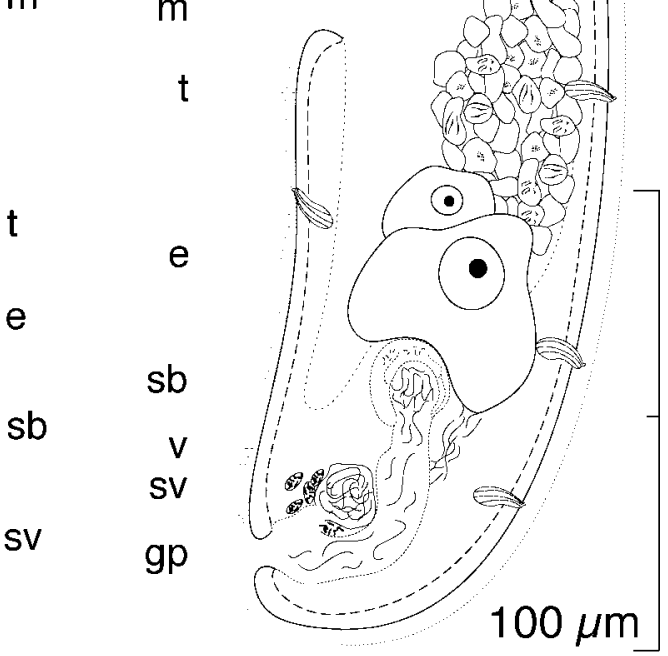

FIGURE 1. Haplogonaria amarilla sp. nov.; reconstructions to show arrangement of organs. A. Dorsal reconstruction of elongated living specimen. B. Sagittal reconstruction of embedded holotype. cs, digestive central syncytium; e, egg; fg, frontal gland; gp, gonopore; m, mouth; rh, rhabdoid gland; sb, seminal bursa; st, statocyst; sv, seminal vesicle; t, testes; v, vagina. 
Frontal organ well developed; cell bodies of frontal glands positioned $\sim 100 \mu \mathrm{m}$ behind frontal pore (Figs. 1B, 2B).

Mouth opening on ventral surface, middle of body. Digestive central syncytium extends from posterior end of frontal glands to level of seminal vesicle.

Ovary presumed to be unpaired, ventral; no more than two eggs-positioned medially—discernible in live and sectioned material (Figs. 1, 2A, C).
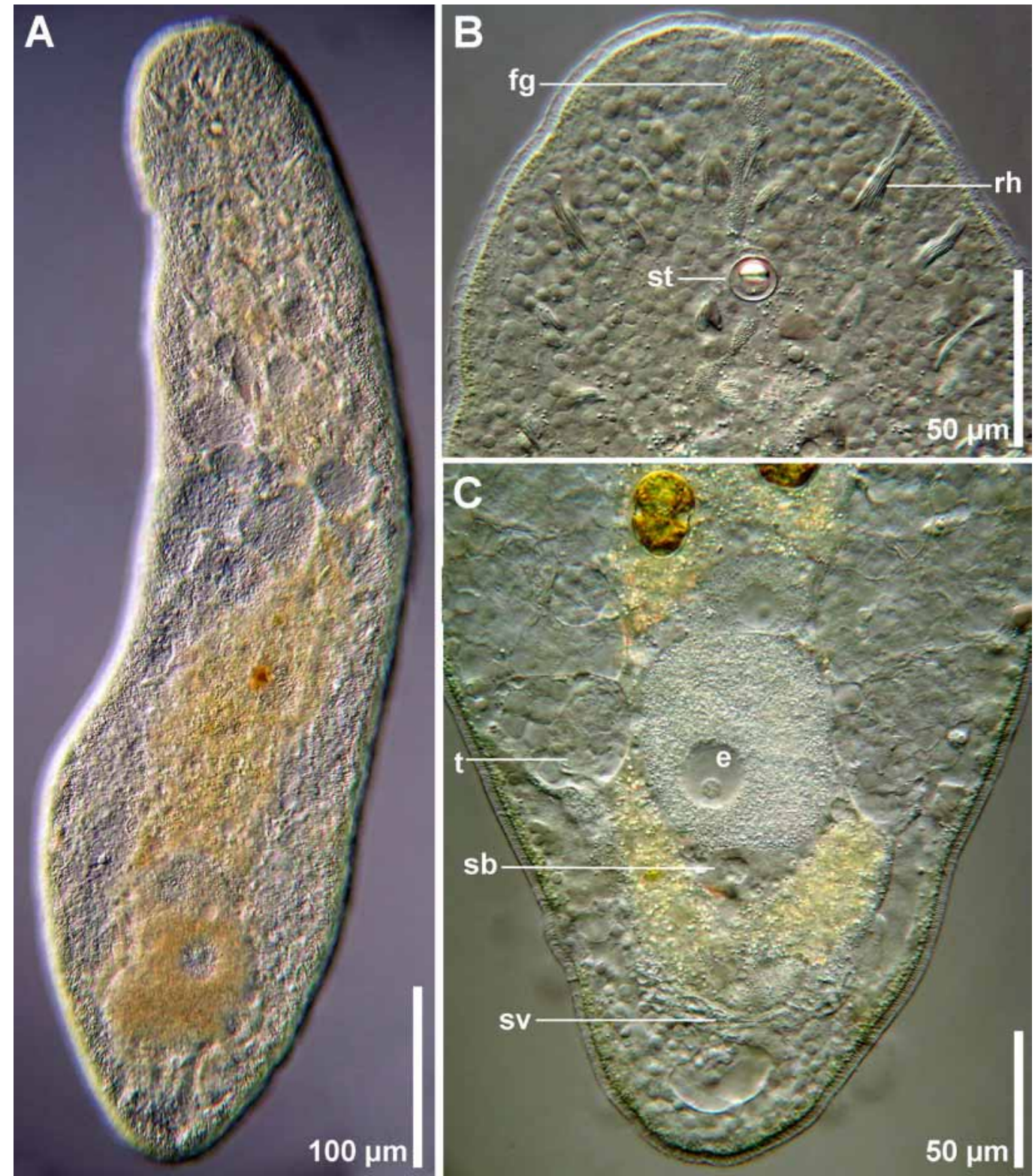

FIGURE 2. Haplogonaria amarilla sp. nov.; photomicrographs of living specimen. A. Dorsal view of whole specimen. B. View of anterior tip. C. View of posterior tip. e, egg; fg, frontal gland; rh, rhabdoid gland; sb, seminal bursa; st, statocyst; sv, seminal vesicle; t, testes. 
Testes paired, dorsal, compact; separate from ovary. Testes extend anteriorly to level of mouth and posteriorly to male copulatory organ.

Common gonopore on ventral surface opens anteriorly to sperm-filled seminal vesicle composed of thin layer of muscle and surrounded on ventral and posterior sides by several conspicuous nuclei (Figs. 1B, 2B, 3B).

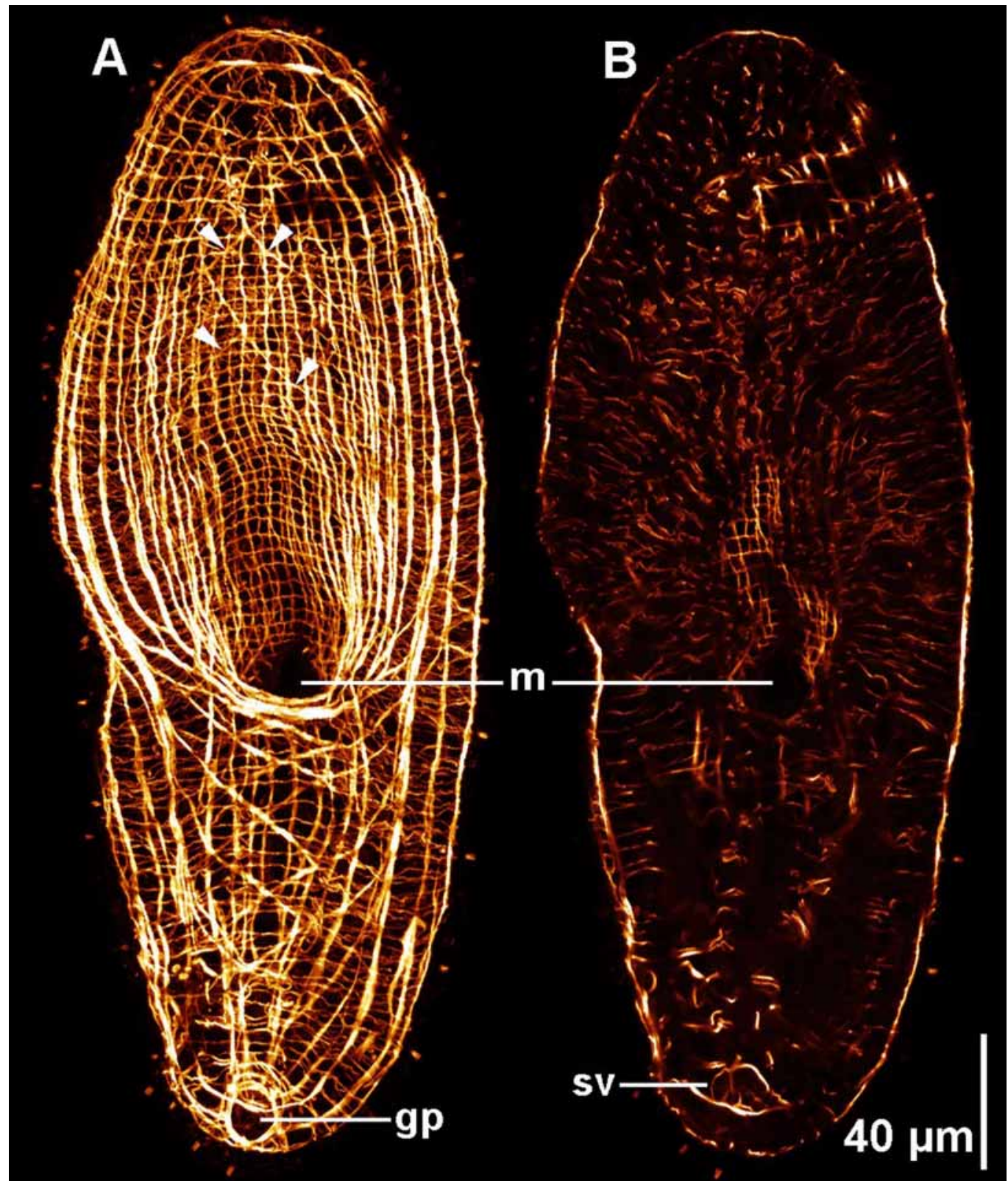

FIGURE 3. Haplogonaria amarilla sp. nov.; whole-mount stained with Alexa-488-labeled phalloidin and viewed with confocal microscopy. A. Projection of ventral body-wall musculature. For explanation of muscle patterns see Hooge (2001). B. Focus on parenchymal musculature. Arrowheads mark ventral diagonal body-wall muscles. gp, common gonopore; m, mouth; sv, seminal vesicle. 

over dorsal side of seminal vesicle to sperm-filled seminal bursa; bursa with well-developed bursal wall (Figs. 1B, 2B).

Remarks. There are presently 14 described species of Haplogonaria that are united in having an unpaired ovary, paired testes, and a seminal bursa that lacks a bursal nozzle. Some species, such as H. arenaria (Ax, 1959), H. elegans Faubel, 1976, and H. stradbrokensis Hooge, 2003 have a non-muscular, or weakly muscular seminal vesicle, while other species, such as H. phyllospadicis Hooge \& Tyler, 2003, and H. simplex Dörjes, 1968, have a strongly muscular seminal vesicle. H. amarilla is more like the former, with only a very thin layer of muscle contributing to the wall of the seminal vesicle (Fig. 3B). It is unusual for members of the Haploposthiidae to have a vagina positioned as it is in this species; that is, opening posterior to, and passing dorsally over the seminal vesicle. Within the Haplogonaria, this configuration of the vagina is shared only with $H$. sinubursalia Dörjes, 1968. In other regards, the vagina and bursa of H. amarilla are dissimilar to that of H. sinubursalia, which has a vagina filled with granular secretions (vesicula granulorum), and a bursa bearing a cap of cells on its proximal wall; both of these features are lacking in H. amarilla.

\section{Family Isodiametridae Hooge \& Tyler, 2005}

Genus Isodiametra Hooge \& Tyler, 2005

Isodiametra bajaensis sp. nov. (Figs. 4-6)

Type Material. Syntypes. AMNH PLATY 1661 and AMNH PLATY 1662, one set of 1.5$\mu \mathrm{m}$-thick serial sagittal sections and one set $1.5-\mu \mathrm{m}$-thick serial frontal sections of epoxyembedded specimen stained with toluidine blue. Paratype. AMNH 1663, epoxy-embedded whole mount.

Type Locality. San Felipe, Baja California, from subtidal medium grained sand from the south side of San Felipe Bay (3058'35.1” N, 11448'22.6” W).

Other Material Examined. Whole mounts for fluorescence imaging of musculature; photographs of living specimens in squeeze preparations, three sets of $1.5-\mu \mathrm{m}$-thick serial sagittal sections and one set of 1.5 - $\mu$ m-thick serial frontal sections of epoxy-embedded specimens.

Etymology. Species name refers to the type locality of Baja California, Mexico.

Description. Examined specimens 280 to $330 \mu \mathrm{m}$ long and 75 to $100 \mu \mathrm{m}$ wide (Figs. 4A, B, 5A). Anterior and posterior ends rounded. Body cylindrical.

Epidermis completely ciliated. Many mucoid glands present. Body colorless in transmitted light, but digestive syncytium has brown and slight green coloring.

Body-wall musculature with circular muscles that encircle the body along entire length of animal; straight longitudinal muscles present between frontal organ and anterior edge of mouth; longitudinal muscles with a longitudinal orientation anteriorly that bend 
medially to cross diagonally over the body; longitudinal-cross-over fibers present in dorsal and ventral body walls; longitudinal muscles in the anterior half of the body that wrap around the posterior rim of the mouth (U-shaped muscles) present in ventral body wall (data not shown).

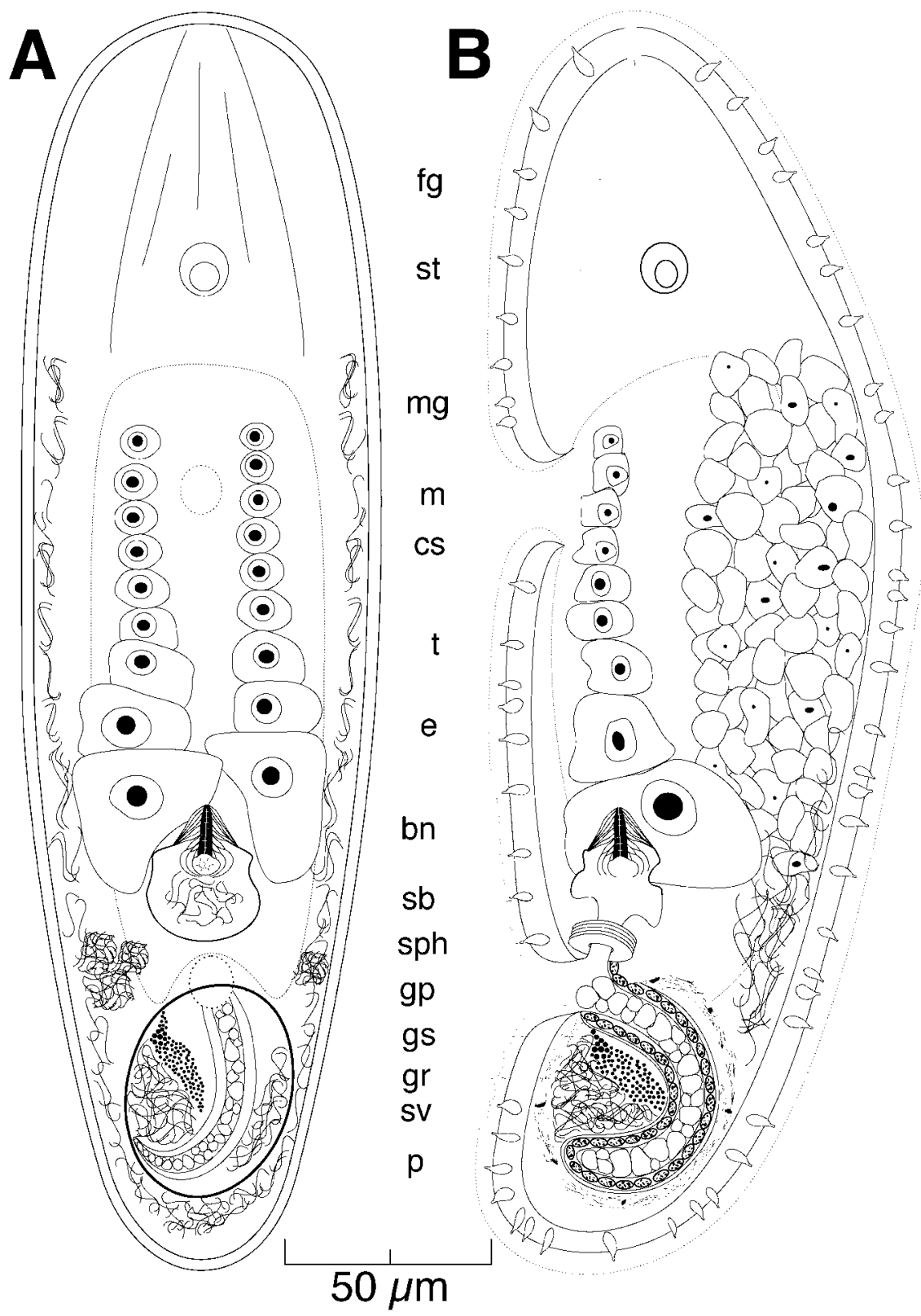

FIGURE 4. Isodiametra bajaensis sp. nov.; reconstructions to show arrangement of organs. A. Dorsal reconstruction of whole organism. B. Sagittal reconstruction of whole organism. bn, bursal nozzle; cs, digestive central syncytium; e, egg; fg, frontal gland; gp, gonopore; gr, granules; gs, glandular secretions; $\mathrm{m}$, mouth; mg, mucoid gland; $\mathrm{p}$, penis; sb, seminal bursa; sph, vaginal sphincter; st, statocyst; sv, seminal vesicle; t, testes. 
Frontal organ well developed. Cell bodies of frontal glands positioned $75 \mu \mathrm{m}$ behind frontal pore (Fig. 4B).

Mouth opening on ventral surface, middle of body. Digestive central syncytium extends from frontal glands posteriorly to male copulatory apparatus.

Ovaries paired, ventral; extend from frontal glands posteriorly to bursal nozzle (Figs. $4 \mathrm{~A}, \mathrm{~B})$.

Testes paired, lateral to eggs; separate from ovary. Testes extend from frontal gland posteriorly to level of the bursal nozzle (Figs. 4A, B).

Common genital pore opens with posterior side opening to male copulatory apparatus, and anterior side opening to vagina (Figs. 4A, B, 5C).

Vagina is positioned directly anteriorly to the male copulatory organ (Figs. 4A, B, 5C). Vagina surrounded by a large muscular sphincter; leads to seminal bursa with well-developed sclerotized bursal nozzle. Lateral extensions of bursal nozzle cells extend posteriorly to form anterior and lateral portions of seminal bursa wall (Figs. 4B, 5C, 6A).

Gonopore opens directly to well-developed, C-shaped tubular penis with outer nonanastomosing longitudinal muscles and inner circular muscles (Figs. 4B, 5C, 6B). Circular muscle fibers are thicker than spaces between fibers. Lumen filled with large spherical glandular secretions (Figs. 4A, B, 5B, C). Penis invaginated into muscular seminal vesicle filled with sperm and small spherical granules that surrounds proximal end of penis.

Remarks. The members of the genus Isodiametra are distinguished from the other 18 genera of the Isodiametridae by the presence of a true seminal vesicle, along with a bursa bearing a single sclerotized bursal nozzle.

The genus Isodiametra contains thirteen described species, seven of which have in common with I. bajaensis the characteristic of a common gonopore. Of these, I. bajaensis is most similar to I. divae (Marcus, 1950) and I. vexillaria (Marcus, 1948), all of which have a male copulatory organ with a $\mathrm{C}$-shaped tubular penis containing glandular secretions in the lumen. The body length of I. bajaensis is similar to that of I. vexillaria $(\sim 300$ $\mu \mathrm{m})$, but shorter than that of I. divae $(\sim 500 \mu \mathrm{m})$. The bursal nozzle of I. bajaensis is like that of I. divae and I. vexillaria in having lateral extensions that extend posteriorly to form the anterior and lateral portions of the bursal wall; however, I. divae's sclerotized portion of the nozzle is short and thick, and I. bajaensis has a long and thin sclerotized nozzle similar to that of I. vexillaria. Isodiametra bajaensis has a wider and thicker vaginal sphincter compared to those of I. vexillaria and I. divae. In addition, the circular muscle fibers in the penis of I. bajaensis and I. divae are thicker than the spaces between the fibers; this is not the case in I. vexillaria.

Diagnostic characters of I. bajaensis include: a C-shaped tubular penis containing glandular secretions in the lumen of the penis, a thick vaginal sphincter, a single, welldeveloped sclerotized bursal nozzle with lateral extensions that extend posteriorly to form anterior and lateral portions of seminal bursa wall, and circular muscle fibers in the penis that are thicker then the spaces between the fibers. 

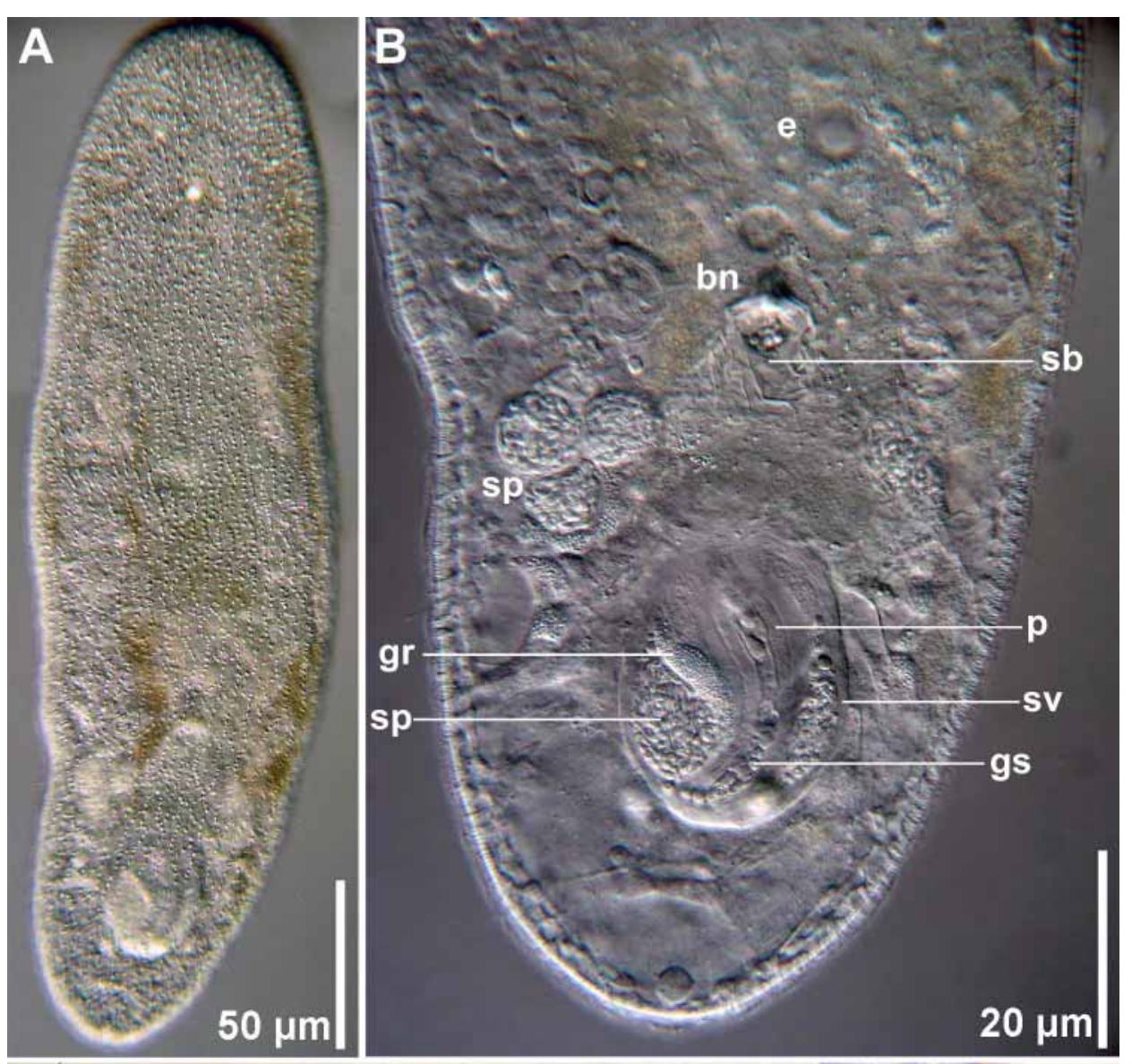

ZOOTAXA

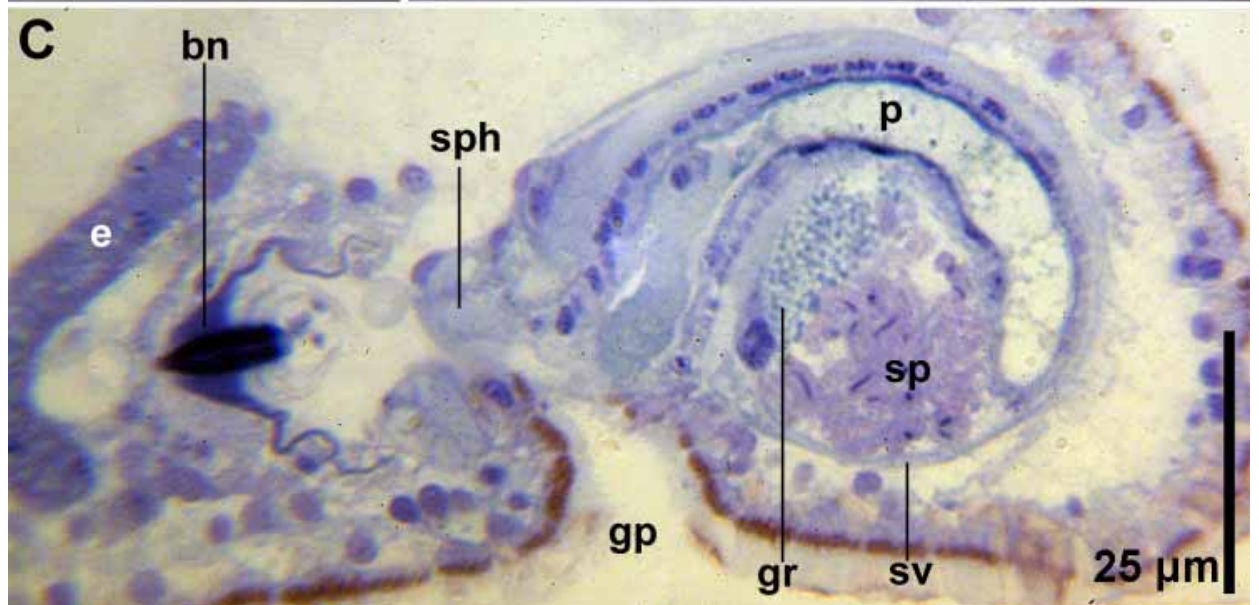

FIGURE 5. Isodiametra bajaensis sp. nov.; photomicrographs. A. Dorsal view of living specimen. B. Dorsal view of posterior. C. Sagittal histological section of posterior. bn, bursal nozzle; e, egg; gp, gonopore; gr, granules; gs, glandular secretions; p, penis; sb, seminal bursa; sp, sperm; sph, vaginal sphincter; sv, seminal vesicle. 

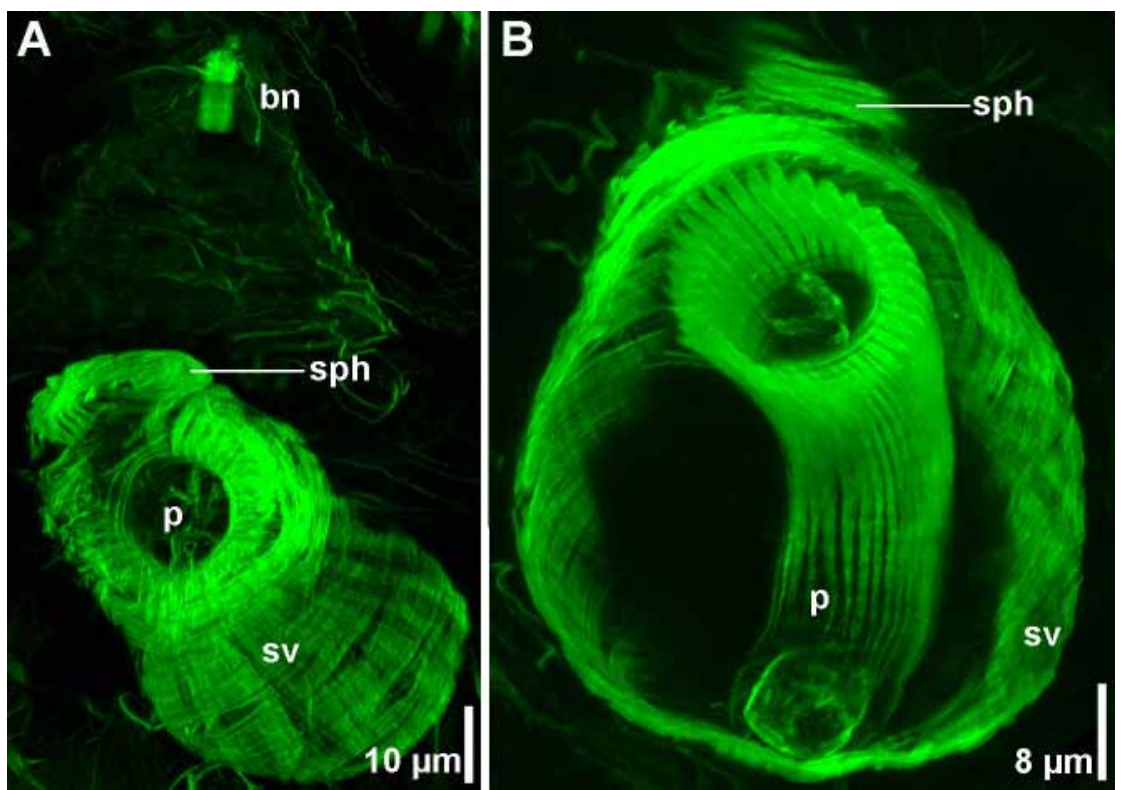

FIGURE 6. Isodiametra bajaensis sp. nov.; whole-mount stained with Alexa-488-labeled phalloidin and viewed with confocal microscopy. A. Projection of musculature associated with reproductive organs including vaginal sphincter. B. Projection showing penis musculature inside seminal vesicle. bn, bursal nozzle; $p$, penis; sph, vaginal sphincter; sv, seminal vesicle.

\section{Family Isodiametridae Hooge \& Tyler, 2005 \\ Genus Praeaphanostoma Dörjes, 1968 \\ Praeaphanostoma gusana sp. nov. (Figs. 7,8)}

Type Material. Holotype. AMNH PLATY 1664, set of $1.5-\mu$ m-thick serial sagittal sections of epoxy-embedded specimen stained with toluidine blue. Paratype. AMNH PLATY 1665 , set of $1.5-\mu \mathrm{m}$-thick serial sagittal sections of epoxy-embedded specimen stained with toluidine blue.

Type Locality. San Felipe, Baja California, from intertidal fine sand from the northwest corner of San Felipe Bay (3101'03.4” N, 11449'50.3” W).

Other Material Examined. Photographs of living specimens in squeeze preparations, and one set of 1.5- $\mu \mathrm{m}$-thick serial sagittal sections of epoxy-embedded specimen.

Etymology. Species name is a derivation of the Spanish gusano, worm.

Description. Mature, living specimens $\sim 400 \mu \mathrm{m}$ long and $\sim 150 \mu \mathrm{m}$ wide (Figs. 7A, $8 \mathrm{~A}, \mathrm{~B})$. Preserved specimens contracted to $\sim 260 \mu \mathrm{m}$ long. Anterior and posterior ends rounded. Body cylindrical.

Epidermis completely ciliated. Rhabdoid glands present. Body colorless in transmitted light, but digestive syncytium with yellow coloration.

Frontal organ well developed. Cell bodies of frontal glands positioned $\sim 110 \mu \mathrm{m}$ behind frontal pore (Fig. 7B). 

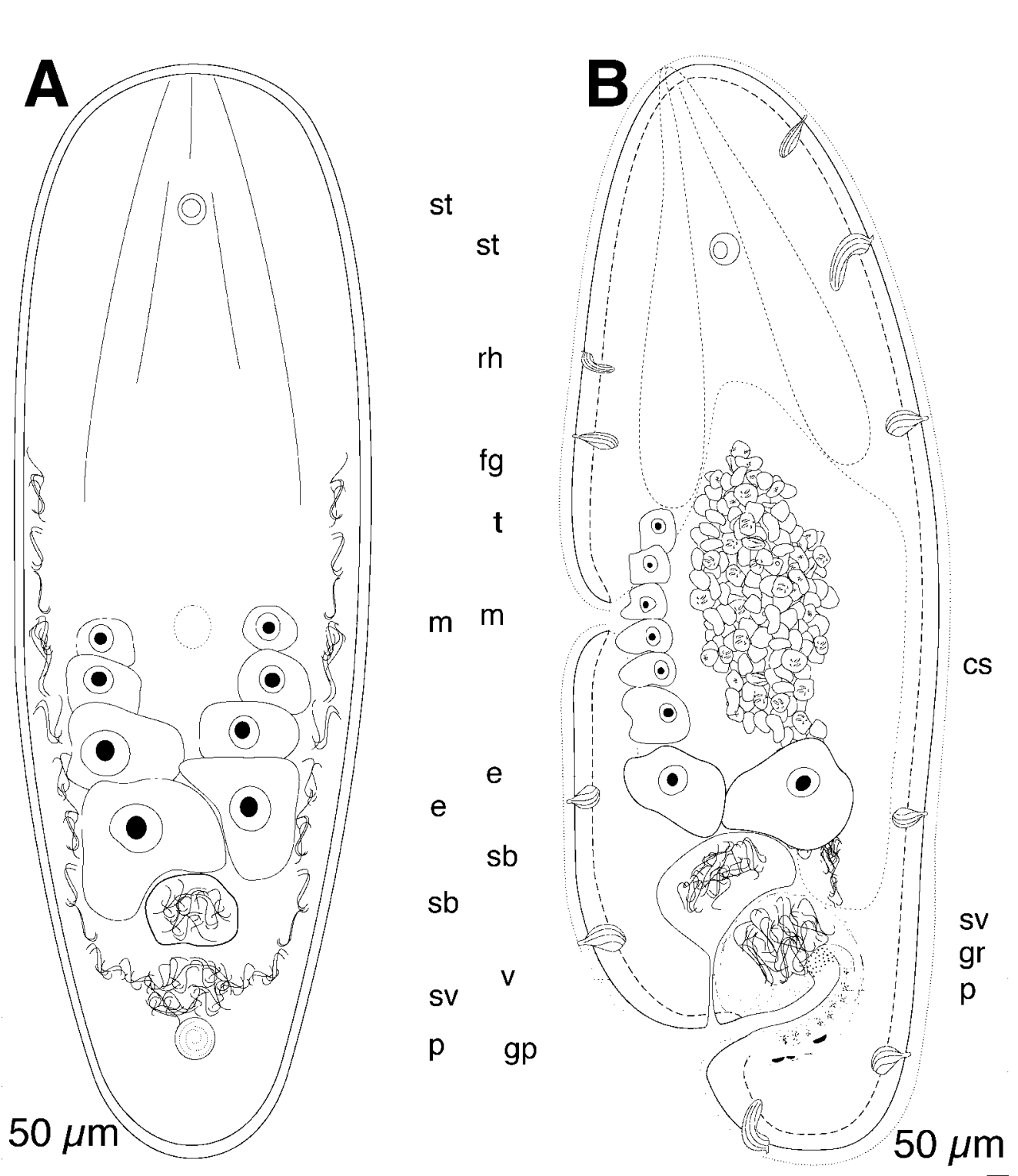

FIGURE 7. Praeaphanostoma gusana sp. nov.; reconstructions to show arrangement of organs. A. Dorsal reconstruction of whole organism. B. Sagittal reconstruction of whole organism. cs, digestive central syncytium; e, egg; fg, frontal gland; gp, gonopore; gr, granules; m, mouth; p, penis; rh, rhabdoid gland; sb, seminal bursa; st, statocyst; sv, seminal vesicle; t, testes; v, vagina.

Mouth opening on ventral surface, middle of body. Digestive central syncytium extends from frontal glands posteriorly to male copulatory apparatus.

Ovaries paired, ventral; extend from frontal glands posteriorly to seminal bursa (Figs. 7A, B).

Testes paired, lateral to eggs; separate from ovary. Testes extend from frontal gland posteriorly to level of seminal bursa (Figs. 7A, B). 

apparatus (Figs. 7A, 8C).

Narrow vagina extends anteriorly along posterior side of seminal vesicle; opens to seminal bursa (Figs. 7B, 8C). Seminal bursa with well-defined bursa wall. Bursa filled with sperm in living specimens, but sperm absent in fixed specimens (Fig. 8C). Bursa without bursal appendage.

Gonopore opens directly to well-developed, curved penis with outer longitudinal muscles and inner circular muscles (Figs. 7B, 8C). Tip of penis with a cluster of granules (Kornsekret, sensu Dörjes 1968). Penis invaginated into muscular seminal vesicle filled with sperm clustered to anterior side of penis.
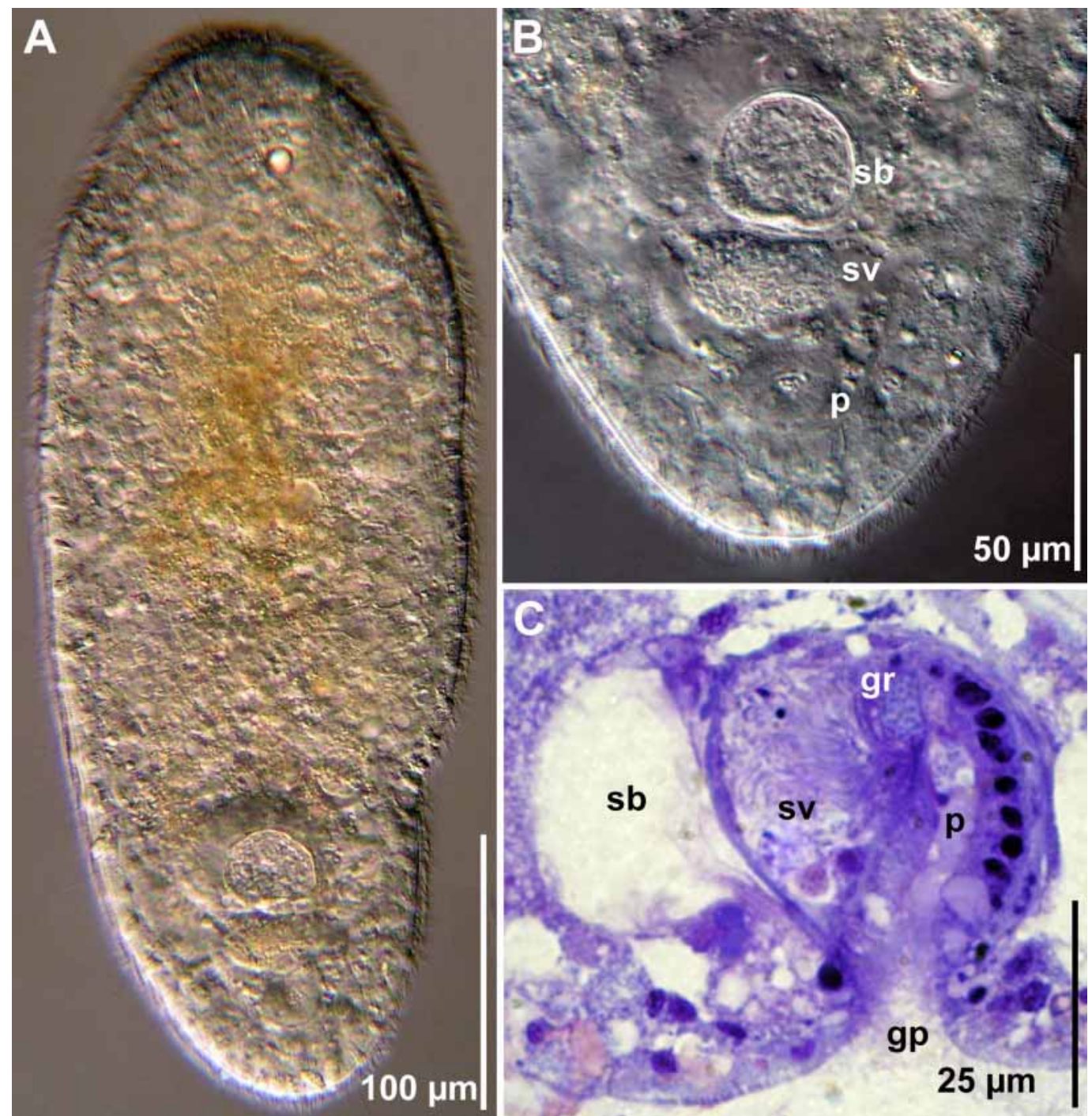

FIGURE 8. Praeaphanostoma gusana sp. nov.; photomicrographs. A. Dorsal view of living specimen. B. Dorsal view of posterior. C. Sagittal histological section of copulatory organs. gp, gonopore; gr, granules; p, penis; sb, seminal bursa; sv, seminal vesicle. 
Remarks. The genus Praeaphanostoma is composed of 10 species that can be distinguished from other members of the Isodiametridae by their possession of a walled seminal bursa that lacks an appendage such as a bursal nozzle, and their lack of eyespots (as found in Ancylocirrus), or a long tubular, ciliated vagina (as found in Bursosaphia). Praeaphanostoma gusana has a single gonopore, a slightly curved penis with granules clustered at the tip of the lumen, and is without a sphincter on the vagina. While all of these are common features in this genus, no other member of Praeaphanostoma has this exact suite of characters.

\section{Acknowledgments}

We are grateful to Dr. Wolfgang Sterrer who helped with the collection of this material. Special thanks go to Drs. Nick Holland and Linda Holland of Scripps Institution of Oceanography for providing accommodations and laboratory space. Thanks also to Dr. William Newman for providing microscope equipment. This material is based upon work supported by the National Science Foundation under Grant Nos. 0118804 and 9977643.

\section{References}

Crezée, M. (1975) Monograph of the Solenofilomorphidae (Turbellaria: Acoela). Internationale Revue gesamten Hydrobiologie, 60, 769-845.

Dörjes, J. (1968) Die Acoela (Turbellaria) der deutschen Nordseekste und ein neues System der Ordnung. Zeitschrift fr Zoologische Systematik und Evolutionsforschung, 6, 56-452.

Giberson, R.T. \& Demaree Jr., R.S. (1995) Microwave fixation: understanding the variables to achieve rapid reproducible results, Microscopy Research and Techniques, 32, 246-254.

Hooge, M.D. (2001) Evolution of body-wall musculature in the Platyhelminthes (Acoela, Catenulida, Rhabditophora), Journal of Morphology, 249, 171-194.

Hooge, M.D. (2003) Two new families, three new genera, and four new species of acoel flatworms (Acoela, Platyhelminthes) from Queensland, Australia, Cahiers deBiologie Marine, 44, 275298.

Hooge, M.D. \& Smith J.P.S. (2004) New acoels (Acoela, Acoelomorpha from North Carolina, Zootaxa, 442, 1-24.

Hooge, M.D. \& Tyler S. (2001) Interstitial acoels (Platyhelminthes: Acoela) from Bermuda, Proceedings of the Biological Society of Washington, 114, 414-426.

Hooge, M.D. \& Tyler S. (2003a) Acoels (Platyhelminthes, Acoela) from the Atlantic coast of North America, Meiofauna Marina, 12, 7-36.

Hooge, M.D. \& Tyler S. (2003b) Two new acoels (Acoela, Platyhelminthes) from the central coast of California, Zootaxa, 131, 1-14.

Hooge, M.D. \& Tyler S. (2005) New tools for resolving phylogenies: a systematic revision of the Convolutidae (Acoelomorpha, Acoela). Zoological Systematics and Evolutionary Research, $43,100-113$.

Smith, J.P.S. \& Tyler, S. (1984) Serial sectioning and staining of resin-embedded material for light microscopy: recommended procedures for micrometazoans. Mikroskopie, 41, 259-270.

Tyler, S., Schilling, S., Hooge, M. \& Bush, L.F. (comp.) (2005) Turbellarian taxonomic database. 

tron microscopy, Nature, 216, 173-14.

Sterrer, W. (1971) Gnathostomulida: problems and procedures. In: N.C. Hulings (Ed) Proceedings of the First International Conference on Meiofauna. Smithsonian Contributions to Zoology, 76, Washington, D.C.: Smithsonian Institution Press, 9-15. 